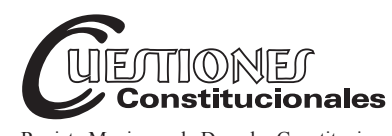

Revista Mexicana de Derecho Constitucional Núm. 42, enero-junio 2020

\title{
Discreción judicial, razonabilidad y control de constitucionalidad*
}

\author{
Judicial Discretion, Reasonableness and Judicial Review
}

\section{Felipe Ignacio PAREDES PAREDES**}

RESUMEN: El trabajo analiza la importancia del concepto de test de constitucionalidad en el juicio de constitucionalidad de las leyes, especialmente en los casos de discreción legislativa. Se estudian las implicaciones de la utilización de un determinado test y cómo esta decisión influye en el resultado. Con este propósito, se caracteriza el control de constitucionalidad como un control de razonabilidad. En la medida de que existen distintos modelos de razonabilidad, ello se traduce en la existencia de diversos test de constitucionalidad. El artículo discute esta hipótesis a partir de tres estándares de amplia difusión en el derecho comparado: el test de Wednesbury, el test de proporcionalidad y el test de escrutinio estricto. Dicho ejercicio muestra cómo un precepto impugnado puede tener distinta suerte y que el juicio de constitucionalidad puede arrojar resultados distintos en cada uno de estos casos.

Palabras clave: jurisdicción constitucional, Estado de derecho, interpretación del derecho, derecho constitucional, jurisprudencia.
ABSTRACT: The paper analyzes the importance of the concept of constitutionality test in the judicial review of the legislation, especially when the Constitution delivers to the Congress discretionary powers. The implications of using a specific test are as important as this decision will determine that the law be uphold or invalidate. For this purpose, judicial review of legislation is characterized as a control of reasonableness. Due to there are different models of reasonableness, consequently it produces the existence of different models of constitutionality tests. The article is focused on three widely diffused tests in comparative law: The Wednesbury test, the proportionality test and the strict scrutiny test. This exercise puts clearly in evidence how the constitutional rulings yield different results in each of these cases.

Keywords: Constitutional Court, Rule of Law, Interpretation of the Law, Constitutional Law, Jurisprudence.

* Artículo elaborado en el marco del proyecto Fondecyt de iniciación a la investigación núm. 11150828, "Proporcionalidad y deferencia en el control de constitucionalidad de las leyes", del cual el autor es investigador principal.

** Profesor de derecho constitucional de la Universidad Austral de Chile. Correo electrónico: felipe.paredes@uach.cl; ORCID: https://orcid.org/0000-0003-0232-1919. 
SUMARIO: I. Introducción. II. Estado de derecho y control jurisdiccional. III. Estándares y control de constitucionalidad. IV. Corolario: elegir el estándar de control. V. Corolario: eligiendo el estándar adecuado de control. VI. Bibliografía.

\section{INTRODUCCIÓN}

En el contexto del Estado constitucional de derecho, la Constitución representa la norma de mayor jerarquía del sistema jurídico, al mismo tiempo que dota de unidad al derecho. Desde este punto de vista, la labor que realiza un tribunal constitucional, ${ }^{1}$ al controlar la constitucionalidad de las normas, es de absoluta relevancia: de él depende la última palabra acerca de si una norma se encuentra o no dentro del marco de la Constitución. Por esta razón, los órganos del Estado y los particulares necesitan conocer en qué casos sus acciones se encuentran proscritas por la carta fundamental. Sin embargo, esto último no es siempre una tarea sencilla.

En términos generales, una norma inconstitucional es aquella que contraviene el texto de la Constitución, pero esta idea está lejos de ser uniforme, debido a que la Constitución contiene normas de diferente naturaleza. Este trabajo aborda uno de los casos problemáticos: el control de constitucionalidad del legislador en los casos en los que la Constitución le asegura a dicho órgano un espacio de discreción a través de un margen de libertad de configuración normativa. Esta situación se produce en todos los casos en los que la Constitución le impone al legislador la necesidad de conseguir un resultado, pero le entrega libertad en cuanto a los medios. ${ }^{2}$

Este artículo busca reconstruir el razonamiento que, con carácter general, realiza el juez constitucional para evaluar la constitucionalidad de la ley en esos casos. La tesis que formula consiste en que, los distintos elementos que forman el juicio de constitucionalidad pueden ser sistemati-

1 La expresión tribunal constitucional debe entenderse a estos efectos como sinónima de todo tribunal con atribuciones de realizar control constitucional.

2 Por ejemplo, el artículo 21 de la Constitución de Colombia dispone: "Se garantiza el derecho a la honra. La ley señalará la forma de su protección"; o el artículo 13 de la Constitución de Perú asegura el derecho: "A asociarse y a constituir fundaciones y diversas formas de organización jurídica sin fines de lucro, sin autorización previa y con arreglo a ley". 
zados en una estructura epistémica denominada test de constitucionalidad. De esta tesis principal se desprenden tres tesis secundarias:

- En el derecho constitucional contemporáneo el juicio de constitucionalidad se ha convertido, para estos casos, en un juicio de razonabilidad, por lo que el test de constitucionalidad evalúa, en definitiva, la razonabilidad de la ley.

- La razonabilidad es un concepto polisémico, lo que da lugar a la existencia de distintos tipos de test de constitucionalidad, contando cada uno con un modelo de razonabilidad particular.

- La elección del test influye sustantivamente en el resultado de la evaluación y configura relaciones competenciales entre los órganos.

Esta estructura permite explicar la complejidad y diversidad del instrumental técnico a partir del cual se formula el juicio de constitucionalidad frente a la ausencia de criterios claros, al mismo tiempo que comprende cómo se pueden producir resultados disímiles en la solución del mismo problema jurídico, puesto que la elección del test de constitucional es un ámbito normalmente no reglado. Por el contrario, esta decisión se expresa usualmente a través de decisiones jurisprudenciales, con criterios no siempre diáfanos.

Como se trata un ejercicio inicial, este trabajo no pretende una revisión exhaustiva de todos los test de constitucionalidad que existen en la actualidad. Su objetivo es mucho más sencillo: demostrar la importancia de la elección del test en el caso concreto. Para ello se analizan tres ejemplos suficientemente conocidos en el derecho constitucional comparado: el test de Wednesbury, el test de proporcionalidad y el test de escrutinio estricto. En abstracto, todos ellos son susceptibles de utilizarse en cualquier país de Latinoamérica. Por último, sólo se trabajará en una reconstrucción gruesa de cada modelo, dejando de lado los matices existentes entre distintas versiones del mismo test.

Además de esta introducción, el artículo se compone de tres secciones: un marco teórico que reflexiona acerca de cómo se conectan los conceptos de Estado de derecho, discreción y control de constitucionalidad; un análisis de la forma en que el derecho público controla las potestades discrecionales a través de la figura de los test de control; una revisión de distintos 
tipos de test de constitucionalidad y cómo ellos ponen en práctica modelos distintos de racionalidad. Se finaliza con un apartado de conclusiones.

\section{ESTADO DE DERECHO Y CONTROL JURISDICCIONAL}

El Estado constitucional de derecho tiene como una premisa básica la interdicción de la arbitrariedad, la que se origina en el ideal ilustrado de la predictibilidad de las decisiones de los poderes públicos. Según Fallon, a pesar de que el Estado de derecho es un concepto polémico, en términos generales, todas las teorías coinciden en algunos presupuestos esenciales: primero, el Estado de derecho otorga protección contra la anarquía y el estado de naturaleza hobbesiano; segundo, proporciona insumos a las personas para planificar sus asuntos con razonable confianza, ya que hace posible que éstas conozcan las consecuencias de sus acciones; tercero, permite defenderse frente a la arbitrariedad de los poderes públicos. ${ }^{3}$ Este es el concepto mínimo o procedimental de Estado de derecho en el sentido defendido por Raz, para quien el Estado de derecho consiste en que "la gente debe obedecer la ley y ser gobernada por ella" y "que los poderes públicos serán regidos por el derecho y estarán sujeto a él" ${ }^{4}$ Similar es la visión de Lon Fuller, quien utiliza la expresión moral interna del derecho para hacer alusión a ocho condiciones que permiten que el derecho funcione como mecanismo racional de regulación de la conducta. ${ }^{5}$

Adicionalmente, el constitucionalismo contemporáneo se ha interesado también por una dimensión sustantiva del Estado de derecho. Desde esta perspectiva, el Estado de derecho no se satisface sólo con reglas claras, estables y universales que permitan predecir el comportamiento de

3 Fallon, Richard, "The Rule of Law as a Concept in Constitutional Discourse", Columbia Law Review, núm. 97, vol. 1, 1997, pp. 7 y 8.

4 Raz, Joseph, La autoridad del derecho. Ensayos sobre derecho y moral (trad. de Rolando Tamayo), México, UNAM, Instituto de Investigaciones Jurídicas, 1985, pp. 265-267.

5 Fuller, Lon, La moral del derecho, trad. de Francisco Navarro, México, Trillas, 1967, p. 52. Concretamente, los requisitos que formula a este respecto son los siguientes: a) las leyes deben ser generales; b) las leyes deben ser promulgadas públicamente; c) no ser retroactivas; d) deben ser claras, en el sentido que los ciudadanos deben saber qué es lo que la ley manda, prohíbe o permite; e) no contradictorias; f) su cumplimiento no debe ser imposible; g) deben poseer una vocación de permanencia y estabilidad; $h$ ) debe existir una congruencia entre lo que establecen las normas y los órganos de aplicación del derecho. 
los agentes jurídicos, sino que, además, es necesario que las instituciones cumplan con ciertos criterios de justicia material. Dworkin llama a esta idea "concepción centrada en los derechos", puesto que en gran medida dichos principios de justicia se consagran a través de la forma de derechos fundamentales. Esta mirada es claramente más ambiciosa que la anterior, pues supone que cada ciudadano posee derechos y deberes morales con relación al resto de los ciudadanos y derechos políticos con relación al Estado en su conjunto. Según lo anterior, el cumplimiento de las normas no es suficiente para garantizar la justicia: "cuando las normas son injustas, un cumplimiento absoluto puede llevar a grandes injusticias". ${ }^{6}$

La concepción centrada en los derechos posee ilustres detractores, pues uno de sus efectos secundarios es que aumenta los niveles de indeterminación normativa. ${ }^{7}$ Aunque la plena seguridad jurídica nunca ha sido alcanzada en los sistemas jurídicos, en materia constitucional este problema parece agudizarse con una concepción material de Estado de derecho. Al respecto, son conocidos los rasgos semánticos de los enunciados lingüísticos propios de las declaraciones de derechos fundamentales, más vagos y ambiguos que los de la parte orgánica, así como la apertura constante que dichas declaraciones poseen hacia el razonamiento moral. Todo esto parece influir poderosamente en tal rechazo. En efecto, algunos autores han acuñado la expresión "conceptos esencialmente controvertidos", para describir las particularidades del lenguaje constitucional y su incompatibilidad con una tesis que defienda la existencia de interpretaciones unívocas en esta materia. ${ }^{8}$ Del mismo modo, esta particularidad ha alimentado una crítica que cuestiona fuertemente la legitimidad democrática del control de constitucionalidad. ${ }^{9}$

El desafío que representa el reconocimiento y tutela de los derechos fundamentales, desde el punto de vista de la seguridad jurídica, se entronca con uno de los temas clásicos de la teoría del derecho: la existencia de discreción por parte de los operadores jurídicos. A partir de la obra de

6 Dworkin, Ronald, Una cuestión de principios, Buenos Aires, Siglo XXI Editores, 2012, p. 29.

7 Kelsen, Hans, ¿Quién debe ser el defensor de la Constitución?, trad. de R. Brie, Madrid, Tecnos, 1995, p. 33.

8 Gallie, Walter Bryce, "Essentially Contested Concepts", Proceedings of the Aristotelian society, núm. 56, 1955, pp. 167-198.

9 Waldron, Jeremy, "The Core and Uneasy Case for Judicial Review", Harvard Law Review, núm. 121, vol. 7, 2008, pp. 1693-1736. 
Hart, un sector mayoritario de los teóricos del derecho reconoce la existencia de discreción judicial en el ordenamiento jurídico, en general, y en el derecho constitucional en particular. ${ }^{10}$ El punto ha sido de tal relevancia que, en el último siglo, la discreción y su control se ha convertido en uno de los grandes tópicos en esta rama del ordenamiento jurídico.

Esta apretada caracterización permite explicar cuál ha sido el derrotero que se ha seguido en la teoría constitucional en el desarrollo de las herramientas de control de constitucionalidad. Desde mediados del siglo XX, el derecho constitucional se ha ido transformando, en gran parte, en una técnica nomofiláctica, cuya función principal es la revisión de los actos jurídicos de los poderes públicos, fijando criterios que permitan evaluar su actividad combinando seguridad jurídica y justicia material. En esta ecuación la noción de razonabilidad ha adquirido un papel preponderante en el control de conceptos jurídicos indeterminados. Por este motivo, en sede de control de constitucionalidad se ha ido generando un complejo instrumental para lidiar con esta tensión entre justicia y seguridad jurídica. Es justamente a este tipo de técnicas a las que la literatura especializada denomina test o estándar de control.

\section{ESTÁNDARES Y CONTROL DE CONSTITUCIONALIDAD}

En los Estados Unidos de América existe una gran cantidad de literatura acerca del concepto de test o estándar de control en materia de revisión judicial. Según Hofer, ${ }^{11}$ un estándar de control es un "mecanismo que define el alcance de la potestad revisora, fijando la altura de los obstáculos que el acto impugnado debe sortear para considerarse válido". Si esta metáfora es correcta, puede decirse también que un estándar opera como un dispositivo para distribuir competencias entre los distintos órganos públicos, puesto que delimita ámbitos de discrecionalidad en los que el órgano controlado posee inmunidad, no siendo sus actos susceptibles de revisión judicial.

La relevancia de este segundo elemento es tal, que Martha Davis, ${ }^{12}$ señala que "un estándar de revisión define el grado de deferencia o inmu-

${ }^{10}$ Hart, Herbert, El concepto de derecho, Buenos Aires, Abeledo Perrot, 1963, p. 159.

11 Hofer, Ronald, "Standards of Review-Looking Beyond the Labels", Marquette Law Review, núm. 74, 1990, p. 232.

12 Davis, Martha, "Basic Guide to Standards of Judicial Review", South Dakota Law Review, núm. 33, 1988, p. 469. 
nidad que un tribunal revisor debe conceder a las decisiones emanadas de otro órgano". En el mismo sentido, Sullivan agrega que un estándar de control contiene una fórmula que permite equilibrar la discreción que debe poseer un órgano decisor y la necesidad de controlarlo. ${ }^{13}$ Pero, desde luego, la forma clásica de conceptualizar un estándar es la que se realiza en oposición a las reglas como herramienta de control. Según Roscoe Pound, las reglas prescriben consecuencias legales determinadas y detalladas a un conjunto definido de hechos concretos ${ }^{14}$ los estándares, por el contrario, establecen un límite general de conducta permisible que requiere aplicación de acuerdo con las circunstancias de cada caso. ${ }^{15}$

Hoy en día, esta distinción forma parte de la cultura jurídica occidental, a pesar de que sigue siendo objeto de debate. Por ejemplo, Schlag destaca que, si bien es conceptualmente ilustrativa, en la práctica la distinción entre reglas y estándares puede ser tenue. ${ }^{16}$ En realidad, agrega, más que una separación exhaustiva lo que existe es una distinción de grado, puesto que una regla puede estar corrompida por excepciones, al punto de asemejarse más a un estándar, y viceversa, un estándar puede estar regulado en términos más o menos estrictos acercándose a una regla. Estas mismas consideraciones han servido para distinguir entre estándares que permiten llevar a cabo controles con distintas intensidades. En un extremo de la cadena se sitúa la revisión completa del acto, en el otro la no revisión. ${ }^{17}$

La razón por la que el derecho constitucional estadounidense se comenzaron a aplicar estándares es objeto de discusión. Según Aleinikoff, en los Estados Unidos de América aparecieron éstos, primero, en las opiniones mayoritarias de la década de 1930. Ningún juez explicó por qué esa manera era considerada la más apropiada de revisión judicial de la ley, en efecto, señala que el análisis histórico muestra que dichos jueces actuaban sin que notaran que estaban haciendo algo novedoso o controversial. ${ }^{18}$ Similar conclusión obtiene Grimm, para el caso alemán, donde

13 Sullivan, Kathleen, "Foreword: The Justices of Rules and Standards", Harvard Law Review, núm. 106, 1993, p. 57

14 Pound, Roscoe, "Hierarchy of Sources and Forms in Different Systems of Law", Tulane Law Review, núm. 7, 1932, p. 482.

15 Ibidem, p. 485.

16 Schlag, Pierre, "Rules and Standards", UCLA Law Review, núm. 33, 1985, p. 383.

17 Davis, Martha, "A Basic Guide to Standards of Judicial Review", South Dakota Law Review, núm. 33, 1988, p. 471.

18 Aleinikoff, Alexander, "Constitutional Law in the Age of Balancing", Yale Law Journal, núm. 96, vol. 5, 1987, p. 948. 
con posterioridad a la Segunda Guerra Mundial el Tribunal Constitucional Federal recurre frecuentemente a la ponderación como método de solución de conflictos entre derechos fundamentales. ${ }^{19}$ Lo que sí está claro, según el mismo Aleinikoff, es que esta situación constituyó una ruptura importante con el pasado, en respuesta al colapso del conceptualismo y el formalismo del siglo XIX.

Existen estudios que analizan esta cuestión desde el punto económi$\mathrm{Co}^{20} \mathrm{y}$ otros que lo hacen desde el punto de vista político o sociológico. ${ }^{21}$ En realidad, es difícil explicar este fenómeno a partir de una sola causa, siendo más bien probable que varios factores como el análisis económico de las decisiones, el clivaje conservadurismo progresismo, o la propia percepción que tiene la judicatura acerca de su rol en el Estado de derecho, confluyeron para producir este resultado. Como sea, en el siglo XX y lo que va del XXI, el derecho público en general ha adoptado una dogmática de estándares más que una dogmática de reglas como técnica revisora, para casos en lo que hay que evaluar es la discreción legislativa.

Ahora bien, esto no significa la desaparición absoluta de una jurisdicción constitucional fundada en reglas. Por ejemplo, en países como los Estados Unidos de América o Chile, un modelo de control basado en reglas denominado originalismo ha recibido apoyo en parte importante de la doctrina y la jurisprudencia. Sin embargo, a causa de las propias limitaciones de las tesis originalistas, el control por estándares ha ido ganando terreno en la aplicación de la Constitución, e incluso en un país con profunda tradición formalista como Chile, dicho control ha tenido una importancia cada vez más creciente. ${ }^{22}$

La "estandarización" del derecho constitucional supone un desafío intelectualmente complejo, pues hace evidente la necesidad de dilucidar qué es lo revisable para el juez constitucional. Si la Constitución reconoce al legislador un margen de configuración normativa, en definitiva, le está

19 Grimm, Dieter, "Proportionality in Canadian and German Constitutional Jurisprudence", University of Toronto Law Journal, núm. 57, 2007, pp. 383-397.

20 Kaplow, Louis, "Rules versus Standards: An Economic Analysis", Duke Law Journal, núm. 42, vol. 3, 1992, pp. 557-629.

21 Sullivan, Kathleen, "Foreword: The Justices of Rules and Standards", Harvard Law Review, núm. 106, 1993, pp. 22-123.

22 Martínez, José y Zúñiga, Francisco, "El principio de razonabilidad en la jurisprudencia del Tribunal Constitucional", Estudios Constitucionales, núm. 9, vol. 1, 2011, pp. 211-214. 
garantizando un ámbito de discreción. En términos generales, la solución que ha adoptado el derecho constitucional ha sido replicar las técnicas del derecho administrativo para controlar las potestades discrecionales de las administraciones públicas. La justificación para ello es más o menos similar: en el Estado constitucional de derecho toda la actividad pública está sometida a control, incluso aquella que se funda en poderes discrecionales, la que está sujeta, al menos, a un control de razonabilidad como límite general.

Sin embargo, se debe tener presente que la existencia de espacios de discreción obedece a factores diversos en una y otra rama del derecho. En el derecho administrativo, los espacios de decisión discrecional responden normalmente a un componente de diseño institucional; en cambio, en materia constitucional, la existencia de discreción no siempre es un producto deliberado, sino más bien es la consecuencia no deseada del tipo de lenguaje utilizado en los textos constitucionales. En cualquier caso, el resultado es que, en ambos sectores del derecho público, el control de la discrecionalidad se ha convertido en uno de los ámbitos más desafiantes de dichas disciplinas: ante la imposibilidad de contar con reglas precisas, el control a través de estándares ha sido la alternativa predilecta del Estado de derecho de nuestros días. Es en este contexto que los distintos test de constitucionalidad han emergido como una herramienta que permite a los tribunales instrumentar la revisión judicial y delimitar los ámbitos de discreción de los poderes públicos.

Si bien actualmente el test de proporcionalidad es el mecanismo predominante a nivel comparado que cumple esta función, existen otras opciones análogas que no pueden ser descartadas de antemano, pues siguen utilizándose en varios sistemas jurídicos. El asunto no es trivial puesto que, por regla general, en el derecho comparado la Constitución no señala cuál es el test que debe aplicar el juez constitucional, quedando dicha decisión a su arbitrio, lo que incide directamente en el resultado.

\section{COROLARIO: ELEGIR EL ESTÁNDAR DE CONTROL}

En la mayoría de los sistemas constitucionales no existe una única fórmula para juzgar la constitucionalidad de la libertad de configuración normativa del legislador. Para comprobar esta hipótesis se analizarán tres tipos de estándares de constitucionalidad. Cada modelo estará representado princi- 
palmente por un caso paradigmático, aunque cada uno de ellos pertenece a una familia de estándares. En esta oportunidad se soslayarán dichos matices, interesándonos más por una reconstrucción gruesa de cada modelo. Ello no quiere decir que dichas diferencias no puedan ser relevantes en otros ámbitos, pues lo que nos interesa es demostrar que el juicio de constitucionalidad adquiere formas diferentes según el estándar que se utilice.

Para ello, es necesario partir señalando que todo test de constitucionalidad comparte los siguientes elementos: a) una serie de argumentos enmarcados en una teoría de la interpretación constitucional que permite dilucidar la (in)constitucionalidad de la norma en cuestión; $b$ ) un umbral de lo constitucionalmente permisible, y $c$ ) reglas procedimentales sobre cargas de la argumentación y distribución de la incertidumbre.

La forma cómo se relacionan todos estos elementos en cada test está determinada por una manera específica de razonar. Pero dado que existen distintas maneras de entender la razonabilidad, el resultado es la existencia de varios tipos de estándares. Por ahora, interesa mostrar cómo cada modelo de razonabilidad considera apropiados argumentos diferentes, sitúa el umbral en latitudes distintas o establece cargas o presunciones en favor o en contra de algunos de los litigantes.

\section{Los estándares del tipo test de Wednesbury}

Es usual en el common law que los estándares se hayan establecido jurisprudencialmente. En materia de revisión judicial también se ha seguido esta tendencia. Los tribunales ingleses han sido particularmente activos e innovadores durante los últimos 30 años, en la definición de criterios de control de la actividad de los poderes públicos. ${ }^{23}$ Históricamente, el principio de división de poderes y la inexistencia de una Constitución escrita, impidieron que en el Reino Unido existiera control de constitucionalidad y condicionaron a que el control de la administración se llevara a efecto únicamente respecto de aspectos procedimentales. No obstante, en las últimas décadas se ha visto una evolución que apunta también al control de aspectos sustantivos. Fundamental en este proceso fue la adopción del test de Wednesbury. ${ }^{24}$

${ }^{23}$ Whittaker, Simon, "El precedente en el derecho inglés: una visión desde la ciudadela", Revista Chilena de Derecho, núm. 35, vol. 1, 2008, p. 68.

24 Peiris, Gamini, "Wednesbury Unreasonableness: The Expanding Canvas", The Cambridge Law Journal, núm. 46, vol. 1, 1987, p. 53. 
Se trata de un estándar que se genera a partir de la sentencia Associated Provincial Picture Houses Ltd. $v$ Wednesbury Corporation. ${ }^{25}$ Más concretamente, el test se aplicó en su formulación original al control de los actos de la administración del Estado, aunque su evolución en el derecho británico y su difusión hacia otros ordenamientos de la tradición del common law, lo han convertido también en un test de constitucionalidad. Influyó en este resultado el hecho de que, varios de los países tributarios de la tradición jurídica británica, han adoptado sistemas de control de constitucionalidad fuertes (por ejemplo India, Singapur, entre otros). El test se inspira precisamente en uno de los pilares de dicha tradición, al tener por objeto controlar el ejercicio de los poderes públicos, pero sin que la actividad de los tribunales sustituya a los órganos políticos en los fundamentos de las decisiones de los órganos con competencia para adoptarlas. ${ }^{26}$

La fórmula clásica fue acuñada por Lord Greene en la señalada sentencia. Según ésta, una medida o política pública dictada por una autoridad, en ejercicio de una facultad legal, puede ser anulada por un tribunal, sólo "si la decisión en una materia de su competencia es tan exorbitante que ninguna autoridad razonable jamás la habría adoptado". El test de Wednesbury entiende como irrazonable el error craso y es allí donde sitúa el umbral de anulabilidad. Esto excluye del ámbito de revisión las diferencias de opinión, que bien puede existir entre personas sensatas. La distinción crucial, con respecto a entender el sentido de la fórmula Wednesbury, es aquella entre un ejercicio equivocado e irrazonable del juicio. Aunque no es indispensable la existencia de mala fe, la decisión impugnada debe contener algún componente de perversidad, arbitrariedad, capricho o absurdo que permita excluir la posibilidad de un ejercicio meramente erróneo de la discreción conferida por una norma jurídica. ${ }^{27}$

En una primera etapa se entendió que el test procuraba evitar decisiones reñidas con las reglas de la lógica, aquellas meramente arbitrarias o azarosas (por ejemplo, consultando un oráculo o lanzando una moneda al aire). Sin perjuicio de que estos supuestos no se pueden descartar totalmente, la

25 Associated Picture Houses Ltd. vs. Wednesbury Corpn, 1948, 1 KB 223, pp. 228-230.

26 Fordham, Michael, "Wednesbury”, Judicial Review, núm. 12, vol. 4, 2007, pp. 266.

27 Peiris, Gamini, op. cit., p. 56. 
verdad es que son infrecuentes..$^{28}$ Por esta razón, el test ha sido reformulado en los últimos años para darle mayor utilidad. En 1985 en Council of Civil Service Unions v Minister for the Civil Service, ${ }^{29}$ el ponente Lord Diplock, señaló que la irracionalidad del test consistía en "una decisión que es tan escandalosa en su desafío a la lógica o a las normas morales aceptadas, que ninguna persona sensata podría haberla adoptado". Al invocar las normas morales generalmente aceptadas, la fórmula de Lord Diplock amplió el alcance del test, aceptando que los poderes públicos pueden ser revisados en sus fundamentos en una dimensión diferente de la anterior. En cualquier caso, ambas formulaciones del test reflejan una concepción subyacente, en la que los tribunales deben interferir sólo en situaciones extremas.

A partir de la aprobación de la Ley de Derechos Humanos de 1998, la fórmula de Diplock permitió que el test se adoptara como una manera de evaluar la observancia de sus disposiciones, por parte de los poderes públicos. Incluso, recientemente el estándar ha sido aplicado con distintos niveles de rigurosidad, por ejemplo, menos estricto para asuntos relativos a cuestiones de regulación económica y más exhaustivo cuando existen derechos humanos involucrados. Si bien es cierto, hoy el test de Wednesbury ha perdido terreno frente al test de proporcionalidad, no ha desaparecido por completo. En la actualidad, no sólo ha sido capaz de sobrevivir en paralelo a este último, sino que también ha influido en su aplicación.

Este tipo de estándar no sólo es patrimonio del derecho insular y también existe en el derecho continental. El mejor ejemplo es un test denominado control del error manifiesto de apreciación (erreur manifeste d'appréciation), creado originalmente en Francia, primero en la jurisprudencia del Consejo de Estado y luego utilizado por el Consejo Constitucional. Su origen en el Consejo de Estado muestra claramente su pedigrí en tanto herramienta que proviene del derecho administrativo. Según Sánchez Morón, este test consiste en situar el límite de la antijuridicidad donde hay abuso o extralimitación de la discrecionalidad en la apreciación de los hechos o en la valoración de las circunstancias del caso, donde el error sea claro y resulte evidente para cualquier persona

28 Jowell, Jeffrey, "Courts and the Administration in Britain: Standards, Principles and Rights", Israeli Law Review, núm. 22, 1987, p. 416.

29 [1985] AC 374 at 410-11. 
razonable. ${ }^{30} \mathrm{Al}$ igual que en Reino Unido este test en la actualidad convive, al mismo tiempo que suele solaparse, con el test de proporcionalidad. ${ }^{31}$

Otro caso relacionado con los anteriores es el test de justificación racional estadounidense (rational basis test), por el que se controla la legislación económica o social en dicho país. Según Raynor, en los Estados Unidos de América el derecho constitucional contemporáneo se caracteriza por un marco doctrinal en el cual las regulaciones económicas están universalmente sujetas a un nivel mínimo de supervisión judicial. ${ }^{32}$ Este mismo autor añade que la formulación de este test parte de la premisa de que la ley goza de una fuerte presunción de validez y que ésta debe ser conservada "habiendo algún antecedente como indicio de un estado de cosas que permita pensar que la decisión fue adoptada sobre una base racional". ${ }^{33}$ Por esta razón, el Estado no tiene la obligación de producir evidencia para acreditar la racionalidad de la ley impugnada; en cambio, es el requirente quien está obligado a demostrar la irracionalidad y a refutar todos los posibles fundamentos racionales que puedan apoyarla.

\section{Lo estándares de Pareto óptimo}

Un estándar Pareto óptimo permite evaluar la razonabilidad de una decisión sobre la base del concepto de eficiencia. Desde esta perspectiva, es razonable aquella decisión que reduce al máximo los costos de oportunidad en la satisfacción de una necesidad determinada. En este sentido, una mejora de Pareto es un cambio a una asignación diferente entre dos variables en conflicto, que hace que una de ellas satisfaga de mejor forma una necesidad, sin hacer que la otra empeore su posición, dada una determinada asignación inicial de bienes entre ambas. Una asignación se define como "Pareto eficiente" o "Pareto óptimo" cuando no se pueden hacer más mejoras de Pareto. Esta noción de razonabilidad proviene de la teoría económica, pero también tiene aplicaciones en el ámbito del derecho y ha

30 Sánchez, Miguel, "Función, límites y control judicial de la discrecionalidad administrativa", Ius et Veritas, núm. 21, 2011, p. 265.

31 Fabbrini, Federico, "Reasonableness as a Test for Judicial Review of Legislation in the French Constitutional Council", Journal of Comparative Law, núm. 4, 2009, pp. 39-64.

32 Raynor, Austin, "Economic Liberty and the Second-Order Rational Basis Test", Virginia Law Review, núm. 99, 2013, p. 1070.

33 Idem. 
resultado clave en la teoría contemporánea de los derechos fundamentales, a través de la idea de optimización. La tesis conceptual más aceptada acerca de la tipología de las normas de derechos fundamentales es que éstos responden a la categoría de principios, y a su vez, dichos principios pueden ser definidos como mandatos de optimización. ${ }^{34}$

El estándar que mejor representa esta forma de entender la razonabilidad es el test de proporcionalidad. Una reconstrucción básica de su estructura divide su aplicación en tres pasos: idoneidad, adecuación y proporcionalidad en sentido estricto.

- Idoneidad: la medida evaluada que afecta un derecho fundamental es útil para satisfacer un fin legítimo.

- Adecuación: la medida representa la alternativa menos lesiva para el derecho en cuestión.

- Proporcionalidad en sentido estricto: existe una adecuada relación entre medios y fines.

La literatura, en general, reconoce que la fórmula más adecuada para entender el test de proporcionalidad es el óptimo de Pareto. Por ejemplo, Alexy confiesa abiertamente que estos tres pasos expresan en su conjunto la idea de optimización y el principal criterio de optimización es el óptimo de Pareto. Los principios de idoneidad y de necesidad se refieren a la optimización respecto de las posibilidades fácticas, el principio de proporcionalidad en sentido estricto se refiere a la optimización de las posibilidades jurídicas. De todas formas, hay que reconocer que el propio Alexy se resiste a la idea de que el óptimo de Pareto sea la única lógica que domina la última etapa del test. ${ }^{35}$ Sin embargo, existen estudios que muestran que esta ha sido la interpretación más recurrente en los distintos tribunales que aplican el test de proporcionalidad. ${ }^{36}$

Sin perjuicio de lo anterior, no debe perderse de vista que en materia jurídica la utilización del óptimo de Pareto es meramente referencial, metafórica si se quiere, careciendo de la exactitud del análisis econométrico. Sobre esto se ha abierto debate, existiendo autores que postulan derecha-

34 Alexy, Robert, "Los derechos fundamentales y el principio de proporcionalidad", Revista Española de Derecho Constitucional, núm. 91, 2011, p. 13.

35 Idem.

36 Foley, Brian, "The Proportionality Test: Present Problems", Judicial Studies Institute Journal, núm. 1, 2008, p. 71. 
mente la inconmensurabilidad de los principios, es decir, la imposibilidad de medir con magnitudes cuantitativas los niveles de afectación de que pueden ser objeto. ${ }^{37}$ Por esta razón, la mayoría de los modelos de ponderación entre derechos utilizan conceptos meramente referenciales (por ejemplo, afectación grave, intermedia y leve), asumiendo las diferencias entre el razonamiento jurídico y el económico. ${ }^{38}$ Por otra parte, el test de proporcionalidad es también sensible a consideraciones axiológicas o institucionales, característica que no es propia de las herramientas de la teoría económica que le sirve de inspiración. Esto se manifiesta en la última etapa de proporcionalidad en sentido estricto, donde a través de la técnica de la ponderación, el intérprete puede considerar otro tipo de razones que le pueden llevar, excepcionalmente, a respaldar una combinación que refleje un subóptimo en términos paretianos. Sin embargo, esta última posibilidad requiere un especial esfuerzo de justificación.

Como sea, todo esto configura un escenario que permite apreciar claramente los contrastes con el test de Wednesbury: en síntesis, en este caso existe un ámbito de revisión ostensiblemente más intenso; por consiguiente, son mayores las posibilidades de que la norma sea declarada inconstitucional. Más concretamente, basta que el órgano decisor haya optado por una combinación susceptible de una mejora de Pareto, es decir un subóptimo, para que dicha decisión pueda ser revocada por el revisor. Además, en este caso el juicio de constitucionalidad está dominado por consideraciones de fondo, lo que no sucede con la aplicación de un test más deferente.

\section{La navaja de Ockham y los estándares de escrutinio estricto}

El test de escrutinio estricto surge en los Estados Unidos de América y representa un estándar de razonabilidad diverso de los casos anteriores. En

37 Webber, Grégoire, The Negotiable Constitution: On the Limitation of Rights, Nueva York, Cambridge University Press, 2009, pp. 89-100. Al respecto, la crítica plantea en la aplicación de los derechos fundamentales, sobre la base de la ponderación, que no es posible realizar una comparación entre costos y beneficios, como si se tratara de bienes que poseen un contenido económico directo.

${ }^{38}$ Da Silva, Virgilio, "Comparing the Incommensurable: Constitutional Principles, Balancing and Rational Decision”, Oxford Journal of Legal Studies, núm. 31, vol. 2, 2011 pp. 273-301. Este autor manifiesta que, si bien no es posible la aplicación de un modelo que mida matemáticamente las afectaciones, sí se pueden valorar y comparar las afectaciones a los derechos fundamentales. 
el derecho público europeo y latinoamericano encontramos un espécimen de esta clase en el test de igualdad. Para caracterizar el tipo de ejercicio intelectual que contiene, nos podemos ayudar de una forma de razonar que ha recibido la denominación de "principio de parsimonia", también conocido como "navaja de Ockham", formulado originalmente por el filósofo escocés Guillermo de Ockham, es una apelación directa al sentido común y a las máximas de la experiencia, sugiriendo que, permaneciendo igual todas las otras variables, cuando hay dos explicaciones para un fenómeno, la más simple es probablemente la correcta. ${ }^{39}$ Desde su formulación la navaja de Ockham ha sido utilizada en múltiples ramas del conocimiento, incluido, por cierto, el derecho.

Así lo señala Richard Helmholz, para quien el criterio de racionalidad que lo informa ha influido con fuerza en varias áreas del derecho en las que se promueve de diferentes maneras la virtud de la simplicidad..$^{40}$ En otras palabras, se puede afirmar que existen ciertas materias donde la navaja de Ockham nos proporciona una herramienta útil, en contextos de cierta incertidumbre, para justificar una solución por sobre otra. Un ejemplo muy conocido es el derecho antidiscriminatorio, donde se utiliza evaluando la razonabilidad de un tratamiento diferenciado, a través de la noción de categoría sospechosa.

En este contexto, y permaneciendo igual todas las otras variables, la idea de categoría sospechosa permite dar por buena la respuesta más simple a la pregunta de si ha habido discriminación en un trato diferenciado: dado que las categorías sospechosas describen a los grupos que han padecido discriminación estructural en una sociedad determinada, lo más probable es que, un tratamiento diferenciado que causa un perjuicio a uno de estos colectivos es un acto de discriminación. En este sentido, quien pretenda demostrar que dicha tesis es falsa, o que existen razones más profundas, sofisticadas o sutiles en sentido contrario, está sometido a cargas argumentativas y probatorias considerablemente superiores que quien, simplemente, afirme la explicación más sencilla a la luz de las relaciones de poder existentes en una sociedad determinada.

Al respecto, el ejemplo más célebremente conocido es el test de escrutinio estricto (Strict Scrutiny Test) en el derecho estadounidense. Según

39 Wertheimer, Ellen, “Ockham's Scalpel: A Return to a Reasonableness Standard”, Villanova Law Review, núm. 43, vol. 2, 1998, p. 321.

40 Helmholz, Richard, “Ockham's Razor in American Law”, Tulane European \& Civil Law Forum, núm. 21, 2006, p. 116. 
Fallon, este test se aplica frente a un caso que cuestione la constitucionalidad de una norma cuando se aduce que ésta vulnera la "cláusula de igual protección ante las leyes" de la 14a. Enmienda, dado que introduce diferenciaciones fundadas en la raza y en otras "categorías sospechosas". Asimismo, proporciona "la regla de base" bajo la 1a. Enmienda, para evaluar las leyes que regulan el discurso". ${ }^{41}$

De esta forma, para poder limitar o regular estos derechos como la igualdad o la libertad de expresión, se requiere que la medida en cuestión tenga por finalidad, no cualquier interés lícito, sino uno de extraordinaria relevancia (compelling government interest) y que además la medida se ciña estrictamente (narrowly tailored) a la satisfacción de dicho interés. Bajo esta fórmula, las posibilidades de que la norma sea declarada inconstitucional son muy altas. No en vano se ha acuñado el aforismo que dice que este test es: "estricto en la teoría, pero fatal en los hechos". ${ }^{42}$

\section{COROLARIO: ELIGIENDO EL ESTÁNDAR ADECUADO DE CONTROL}

A modo de recapitulación, podemos concluir que la noción de test de constitucionalidad reconstruye adecuadamente el esquema de razonamiento del juez constitucional en los casos en que el legislador cuenta con un margen de discreción para el desarrollo de su función. Un test de constitucionalidad es una estructura epistémica que permite sistematizar los elementos esenciales del juicio de constitucionalidad: una teoría de la interpretación constitucional, un umbral que delimita la inconstitucionalidad de la constitucionalidad y la distribución de las cargas de justificación.

A lo largo de estas páginas se ha mostrado que, no es indiferente la elección del test de control para definir el ámbito de lo constitucionalmente permitido o prohibido, puesto que cada uno de ellos presenta distintos criterios de control. Dicha decisión incide en los espacios de discreción que poseen los poderes públicos para determinar el contenido de las disposiciones de la carta fundamental, lo que, por ende, incide en el resultado final del juicio de constitucionalidad. Por ejemplo, si se asume que el estándar

41 Fallon, Richard, "Strict Judicial Scrutiny", UCLA Law Review, núm. 54, 2006, p. 1269.

42 Gunther, Gerald, "The Supreme Court, 1971 Term-Freword: In Search of Evolving Doctrine on a Changing Court: A Model for a Newer Equal Protection", Harvard Law Review, núm. 86, vol. 1, 1972, p. 8. 
aplicable al caso concreto es un test de Wednesbury, es mayor la tolerancia hacia las atribuciones discrecionales del legislador, que si la opción escogida fuese el test de proporcionalidad. A su vez, el test de proporcionalidad, en cualquiera de sus versiones, es más deferente que el test de escrutinio estricto diseñado por la Corte Suprema de los Estados Unidos de América.

El tema es crucial porque salvo muy pocas excepciones, como por ejemplo la Constitución de Sudáfrica, en los textos constitucionales (o en los tratados internacionales sobre derechos humanos) no existen instrucciones precisas sobre cuál es el estándar idóneo para controlar la observancia de dichas normas, por lo que, a su vez, la elección del test de control es también una decisión jurisprudencial. Igualmente, es importante señalar que también existe evidencia respecto de que los elementos de un estándar pueden ser interpretados de diversa manera en diferentes épocas o países.

Adicionalmente, este análisis muestra con meridiana claridad que la arquitectura de los test de constitucionalidad se encuentra relacionada con la mayor o menor amplitud de los espacios de discreción que conceden al legislador en el desarrollo de su función. Todo esto releva la importancia de la elección del estándar, ya sea como una decisión que toma el propio ordenamiento jurídico una norma escrita o a través de las decisiones jurisprudenciales. Si todo lo anterior es correcto, se trata de información que es esencial para formular con mayor precisión los alcances de la declaración de inconstitucionalidad y el ámbito de las atribuciones que un tribunal constitucional posee en cada caso particular.

\section{BIBLIOGRAFÍA}

AleINIKOFF, Alexei, "Constitutional Law in the Age of Balancing", Yale Law Journal, núm. 96, vol. 5, 1987.

ALEXY, Robert, "Los derechos fundamentales y el principio de proporcionalidad”, Revista Española de Derecho Constitucional, núm. 91, 2011.

DA SILVA, Virgilio, "Comparing the Incommensurable: Constitutional Principles, Balancing and Rational Decision", Oxford Journal of Legal Studies, núm. 31, vol. 2, 2011.

DAvis, Martha, "A Basic Guide to Standards of Judicial Review", South Dakota Law Review, núm. 33, 1988. 
Dworkin, Ronald, Una cuestión de principios, Buenos Aires, Siglo XXI Editores, 2012.

FABBRINI, Federico, "Reasonableness as a Test for Judicial Review of Legislation in the French Constitutional Council", Journal of Comparative Law, núm. 4, 2009.

FALlON, Richard "The Rule of Law as a Concept in Constitutional Discourse", Columbia Law Review, núm. 97, vol. 1, 1997.

FALLON, Richard, "Strict Judicial Scrutiny", UCLA Law Review, núm. 54, 2006.

Foley, Brian, "The Proportionality Test: Present Problems", Judicial Studies Institute Journal, núm. 1, 2008.

FORDHAM, Michael, "Wednesbury", Judicial Review, núm. 12, vol. 4, 2007.

Fuller, Lon, La moral del derecho, trad. Francisco Navarro, México, Trillas, 1967.

Gallie, Walter, "Essentially Contested Concepts", Proceedings of the Aristotelian Society, núm. 56, 1955.

GRIMM, Dieter, "Proportionality in Canadian and German Constitutional Jurisprudence", University of Toronto Law Journal, núm. 57, 2007.

GunTHER, Gerald, "The Supreme Court, 1971 Term-Foreword: In Search of Evolving Doctrine on a Changing Court: A Model for a Newer Equal Protection", Harvard Law Review, núm. 86, vol. 1, 1972.

HART, Herbert, El concepto de derecho, Buenos Aires, Abeledo Perrot, 1963.

Helmholz, Richard, “Ockham's Razor in American Law”, Tulane European \& Civil Law Forum, núm. 21, 2006.

HofER, Ronald, "Standards of Review-Looking Beyond the Labels", Marquette Law Review, núm. 74, 1990.

JOWELL, Jeffrey, "Courts and the Administration in Britain: Standards, Principles and Rights", Israeli Law Review, núm. 22, 1987.

KAPLOW, Louis, "Rules versus Standards: An Economic Analysis", Duke Law Journal, núm. 42, vol. 3, 1992.

Kelsen, Hans, ¿Quién debe ser el defensor de la Constitución?, trad. de Roberto Brie, Madrid, Tecnos, 1995. 
MARTÍNEZ, José y ZÚÑIGA, Francisco, "El principio de razonabilidad en la jurisprudencia del Tribunal Constitucional”, Estudios constitucionales, núm. 9, vol. 1, 2011.

PEIRIS, Gamini, "Wednesbury Unreasonableness: The Expanding Canvas", The Cambridge Law Journal, núm. 46, vol. 1, 1987.

Pound, Roscoe, "Hierarchy of Sources and Forms in Different Systems of Law”, Tulane Law Review, núm. 7, 1932.

RAZ, Joseph, La autoridad del derecho. Ensayos sobre derecho y moral, trad. Rolando Tamayo, México, UNAM, 1985.

SullivAn, Kathleen, "Foreword: The Justices of Rules and Standards", Harvard Law Review, núm. 106, 1993.

SÁNCHEZ, Miguel, "Función, límites y control judicial de la discrecionalidad administrativa", Ius et Veritas, núm. 21, 2011.

SCHLAG, Pierre, "Rules and Standards", UCLA Law Review, núm. 33, 1985.

RAYNOR, Austin, "Economic Liberty and the Second-Order Rational Basis Test", Virginia Law Review, núm. 99, 2013.

WALDRON, Jeremy, "The Core and Uneasy Case for Judicial Review", Harvard Law Review, vol. 121, núm. 7, 2008.

WeBber, Grégoire, The Negotiable Constitution: On the Limitation of Rights, Nueva York, Cambridge University Press, 2009.

WerTHEIMER, Ellen, “Ockham's Scalpel: A Return to a Reasonableness Standard”, Villanova Law Review, núm. 43, vol. 2, 1998.

WHITTAKER, Simon, "El precedente en el derecho inglés: una visión desde la ciudadela”, Revista Chilena de Derecho, núm. 35, vol. 1, 2008.

Fecha de recepción: 12 de noviembre de 2017.

Fecha de aceptación: 4 de mayo de 2019.

Esta obra está bajo una Licencia Creative Commons

Atribución-NoComercial-SinDerivar 4.0 Internacional, IIJ-UNAM. 